\title{
Globe
}

Revue internationale d'études québécoises

\section{Paul Perron : Narratology and Text. Subjectivity and Identity in New France and Québécois Literature. Toronto, Buffalo et London, University of Toronto Press, 2003}

\section{Jaap Lintvelt}

Volume 8, numéro 2, 2005

URI : https://id.erudit.org/iderudit/1000926ar

DOI : https://doi.org/10.7202/1000926ar

Aller au sommaire du numéro

Éditeur(s)

Globe, Revue internationale d'études québécoises

ISSN

1481-5869 (imprimé)

1923-8231 (numérique)

Découvrir la revue

Citer ce compte rendu

Lintvelt, J. (2005). Compte rendu de [Paul Perron : Narratology and Text. Subjectivity and Identity in New France and Québécois Literature. Toronto, Buffalo et London, University of Toronto Press, 2003]. Globe, 8(2), 320-322. https://doi.org/10.7202/1000926ar d'utilisation que vous pouvez consulter en ligne.

https://apropos.erudit.org/fr/usagers/politique-dutilisation/ 
REVUE INTERNATIONALE D'ÉTUDES QUÉBÉCOISES

\section{Paul Perron}

\section{Narratology and Text. Subjectivity and Identity in New France and Québécois Literature. Toronto, Buffalo et London, University of Toronto Press, 2003.}

Paul Perron combine dans cet ouvrage sa spécialisation méthodologique en sémiotique avec ses connaissances des textes non fictionnels et fictionnels canadiens-français et québécois depuis l'époque de la Nouvelle-France jusqu'à la fin des années 1950.

La première partie (Narratology) présente un survol des théories narratologiques depuis les formalistes russes, suivi d'une étude de l'évolution des concepts principaux de la sémiotique d'André Greimas. L'objectif de Perron est de développer ainsi une théorie globale de la production et de la réception, en combinant les idées de l'École sémiotique de Paris (en particulier Greimas) avec celles d'Émile Benveniste (la subjectivité dans le langage) et de Paul Ricœur (l'expérience humaine du temps). La théorie est ensuite appliquée dans une analyse sémiotique de textes, destinée à montrer la formation de l'identité canadienne-française au cours des siècles.

La deuxième partie (Discovery, Conversion, and Colonization) est consacrée aux Voyages en Nouvelle-France de Jacques Cartier et aux Relations des Jésuites. Cartier décrit le premier contact entre l'Européen et les indigènes de l'Amérique du Nord en donnant, par le biais du point de vue stéréotypé de son époque (civilisé versus sauvage), une représentation de l'Autre et de l'altérité, en interprétant les gestes des Amérindiens comme des signes. À son tour, Jean de Brébeuf présente un discours ethnohistorique sur l'organisation sociale, religieuse, politique et culturelle de la société amérindienne. La connaissance de la langue des Hurons et de leur système de valeurs joue un rôle important dans la mission de conversion. L'auteur montre, dans une analyse sémiotique du martyre du missionnaire Isaac Jacques, que le corps sacrifié, comme incarnation du Verbe qui s'est fait chair, incite à la conversion.

La troisième partie (Historiography and the Novel: Nation and Identity) présente une analyse sémiotique de six romans exemplaires. L'analyse des trois premiers montre le rapport identitaire entre l'individu 


\section{RECENSIONS}

et le groupe. C'est ainsi que Les Anciens Canadiens de Philippe Aubert de Gaspé définit l'identité humaine, géographique et historique de trois générations de Canadiens-français avant et après la Conquête britannique de 1759. Patrice Lacombe, quant à lui, décrit les personnages de son roman du terroir La Terre paternelle dans leurs relations avec la famille, le groupe et la nation, en distinguant quatre espaces positifs ou négatifs : la ferme, le village, la ville et la nature sauvage. Maria Chapdelaine de Louis Hémon évoque également quatre espaces, liés à des personnages : la nature sauvage (François Paradis), la ville (Lorenzo Surprenant), la frontière (Eutrope Gagnon) et le village (Laura Chapdelaine). Pour rester fidèle aux valeurs historiques, sociales, culturelles et religieuses, Maria ne doit pas franchir les frontières de la maison et du village, qui garantissent son identité personnelle. La Scouine d'Albert Laberge contraste fortement avec les romans précédents, en donnant une représentation négative, brutale et violente de la vie à la ferme. Au roman rural succède le roman urbain, représenté par Bonbeur d'occasion de Gabrielle Roy. L'analyse sémiotique (objets de valeur ou de désir; mobilité des personnages) montre comment la famille Lacasse, investie de valeurs rurales traditionnelles, essaie de fonctionner en ville dans un monde capitaliste et technologique à l'époque de la Seconde Guerre mondiale. Dans Agaguk d'Yves Thériault, l'action se déroule dans la nature sauvage de la toundra des Inuits. Deux types d'objets de valeur sont distingués : les objets pratiques pour la survie (nourriture, vêtements, outils) et les objets mythiques, représentés par l'amour-passion. Après la mort des parents et la séparation de la tribu, le couple Agaguk et Iriook, caractérisé par l'égalité des deux sexes, jouit d'une sexualité ouverte non culpabilisante. Agaguk définit ainsi une nouvelle identité sexuelle, morale, rationnelle et émotionnelle basée sur le rejet du passé. Perron l'interprète comme le transcodage des réactions personnelles de Thériault à la situation historique au Québec à la fin des années 1950. Le roman annonce ainsi la Révolution tranquille et le remplacement du Canadien-français, avec son idéologie traditionnelle, par un nouveau sujet : le Québécois.

Tous les textes représentatifs qui ont fait l'objet de l'analyse sémiotique de Paul Perron articulent ainsi une problématique identitaire, définissant l'identité personnelle et collective par rapport à l'altérité. Les concepts récurrents dans l'ouvrage sont l'individu par rapport au groupe ; l'identité personnelle en relation avec la collectivité nationale; 


\section{REVUE INTERNATIONALE D'ÉTUDES QUÉBÉCOISES}

la langue, la race et la religion ; ainsi que l'espace relié à l'identité. Tous ces facteurs ont contribué à la formation d'une identité canadiennefrançaise et québécoise.

Jaap Lintvelt

Centre d'études canadiennes, Université de Groningen 